\title{
ON THE CHOICE BETWEEN PROPERTY RULES AND LIABILITY RULES
}

\section{A. MITCHELL POLINSKY*}

When parties can bargain with each other in an externality situation, it is frequently argued that liability rules are preferable to property rules. The case for liability rules is thought to be strongest when the parties behave strategically, when the collective authority responsible for maximizing social welfare has perfect information, and when lump-sum transfers are not available. It is shown here that liability rules are not generally preferable to property rules in these circumstances because of their limited ability to redistribute income between the parties.

In many externality situations the parties in conflict are able to bargain with each other. When there are very few individuals involved, this possibility arises naturally. When the number of parties is large, bargaining of ten can occur because the relevant individuals - victims or injurers - might select a representative to bargain on their behalf, or might have one imposed on them. For example, industry associations, class action law suits, and neighborhood groups all facilitate bargaining solutions to externality problems in the large number case.

As in any bargaining game, there must be rules governing permissible moves and threats. Two kinds of rules have been suggested. ${ }^{1}$ Under both, some outcome - called the entitlement point - is chosen initially by a collective authority as the point from which bargaining will proceed. A property rule gives each party the right to block any deviation from the entitlement point without that party's consent. A liability rule gives each party the right to compensation from the other party for the damages suffered as a result of the other party's deviation from the entitlement point. What distinguishes the liability rule is that the amount of compensation is determined by the collective authority, rather than by negotiation between the parties.

\footnotetext{
- Law School and Economics Department, Stanford University; and National Bureau of Economic Research. Work on this paper was supported by the Ford Foundation, through a grant to the Program for Basic Research in Law at Harvard Law School, and by the National Science Foundation, through a grant (SOC 78-20159) to the law and econonics program of the National Bureau of Economic Research. Any opinions expressed are those of the author and not those of the NBER. Helpful comments were provided by Robert Ellickson, H.E. Frech 111, Stephen Halpert, Daniel Rubinfeld, Steven Shavell, Richard Stewart, and an anonymous referee.

1. The now classic statement of the rules to be considered here is by Calabresi and Melamed (1972). Their discussion has been extended in various ways by, among others, Ellickson (1973, pp. 738-748), Frech (1979), and Polinsky (1979). (The last two papers are discussed briefly in relation to the present paper in notes 6 and 14 below.) See also the Organisation for Economic Co-operation and Development (1976, pp. 63-86).
} 
Under certain conditions, an apparently convincing case can be made for using liability rules rather than property rules. ${ }^{2}$ These conditions are that the parties bargain strategically (in the sense that they fail to reach all Pareto superior agreements), ${ }^{3}$ that the collective authority has complete information about the technology of the externality, and that lumpsum transfers are not available to redistribute income between the parties. ${ }^{4}$ The argument, briefly and loosely stated, follows.

With complete information, the collective authority can, for any entitlement point, design a schedule of liability which will induce the relevant party to choose the "efficient" outcome. ${ }^{5}$ Strategic behavior is circumvented because the other party cannot threaten to block that choice. Although the schedule of liability must be one in which marginal liability equals actual marginal damages at the efficient outcome, inframarginal liability may be greater or less than actual damages. By the appropriate choice of the entitlement point and the liability schedule, it is claimed that any distributional result can be achieved. Thus, the absence of lump-sum transfers is overcome.

In contrast, the collective authority can achieve the efficient outcome using a property rule only by choosing the entitlement point corresponding to this outcome. This is because, given strategic behavior, the parties would not agree to move all the way to the efficient result from any other entitlement point. The unique distribution of income implied by this choice of entitlements cannot be modified by lump-sum transfers. Only by coincidence would this distribution be the preferred one.

This paper shows that under the stated conditions - strategic behavior, perfect information, and the unavailability of lump-sum transfers - liability rules are not generally superior to property rules. The mistake in the argument stems from the fact that, for reasons to be explained in a later section, there is no effective distributional flexibility in the inframarginal liability schedule. Specifically, it will be shown that marginal liability must everywhere equal actual marginal damages. Thus, all of the "gains from trade" from moving from the entitlement point to the efficient outcome are obtained by the party subject to the liability rule.

2. Although no one has stated the case as explicitly as it will be described here, it is implicit in the work of Ellickson (1973, pp. 738-748), Rabin (1977), and the Comment (1978) in the New York University Law Review.

3. Roughly speaking, strategic behavior occurs because each party underestimates the other party's willingness to agree to its position.

4. Although these conditions are the ones which are implicit in the conventional case for liability rules (see note 2 above), it may seern peculiar to assume that the collective authority has complete information about the externality yet cannot use lump-sum transfers. However, in the institutional context in which the problem arises, the collective authority is usually a court, which is not empowered to engage in general redistribution

5. Either party may be the relevant party, depending on the entitlement point; see section III below. The "efficient" outcone refers to the outcome which would be desired if lump-sum transfers were available. 
In contrast, under a property rule the gains from trade could be split between the parties in any way, depending on their relative bargaining strengths. Thus, depending on the distributional preferences of the collective authority, the bargaining outcome under the property rule might be preferable to the outcome under the liability rule. In fact, it will be shown that the range of outcomes in which a liability rule is unambiguously preferable to a property rule may be arbitrarily small.

As the previous discussion indicates, the choice between property rules and liability rules is interesting only if the collective authority has preferences regarding the distribution of income between the parties. Otherwise, given perfect information, the rules are equally desirable since either one can achieve the efficient outcome. Such distributional preferences may seem peculiar when there are literally just two parties involved. However, in practice, many individuals are likely to be affected by the choice of the rule, either because there are numerous other twoparty situations to which the chosen rule would apply, or, as noted earlier, one or both "parties" may represent a large class of individuals.

In section I the externality problem is described. Sections II and III analyze the sets of outcomes under property rules and liability rules, respectively, when there is (actually or effectively) one injurer and one victim. In section IV the choice between the rules is discussed in this context. Section V contains a summary of conclusions. An appendix shows how the analysis is affected by the presence of many victims.

\section{THE PROBLEM}

For simplicity, it is assumed that the externality involves two firms, an active injurer and a passive victim. ${ }^{6}$ The injurer's profits are an increasing (up to a point), strictly concave function of its output and the victim's damages are a strictly increasing, differentiable function of this output. The victim's profits are fixed prior to suffering damages, but there are no fixed profits of the injurer. The injurer's output is assumed to range between (and include) zero output and its profit-maximizing output, and the parties' joint profits are assumed to reach a unique maximum in the interior of this range. Let

$$
\begin{aligned}
& q=\text { output of the injurer, } \\
& \pi(q)=\text { total prof its of the injurer, } \\
& q_{M}=\text { output at which the injurer's profits are maximized, }
\end{aligned}
$$

6. It is assumed that merger does not take place. Strategic behavior provides one possible explanation. To agree to merge the firms would have to decide how to split the gains from trade resulting from the joint-profit maximizing behavior of the merged firm. It is also assumed that new firms cannot enter. To allow for free entry and exit would convert the problem from a "snall number" one to a "large number" one in which bargaining would not be practicable. See Frech (1979) for a discussion of property rules and liability rules in the latter context. (Because injurers and victims do not bargain in his model, he defines the rules differently than here.) 


\section{FIGURE 1}

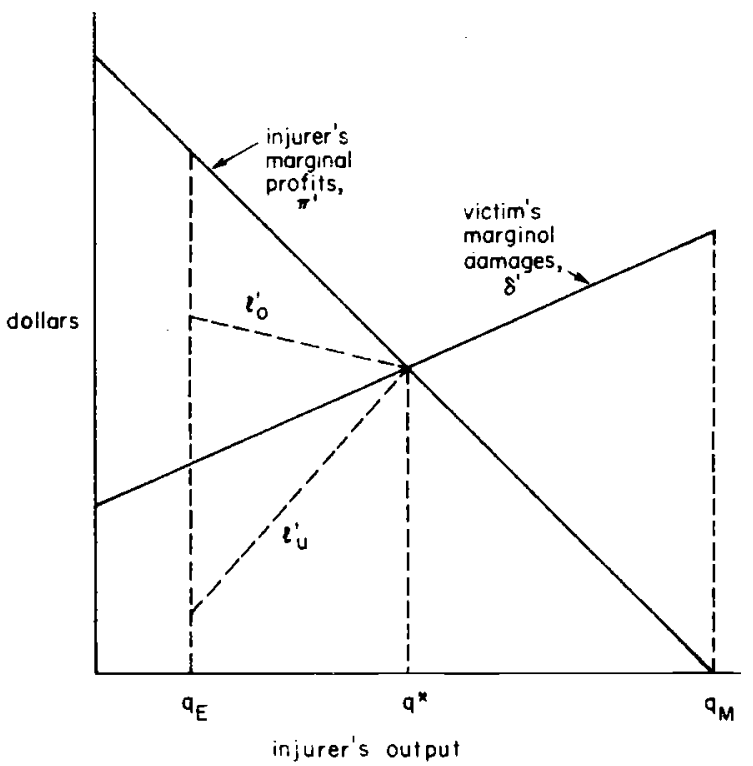

FIGURE 2

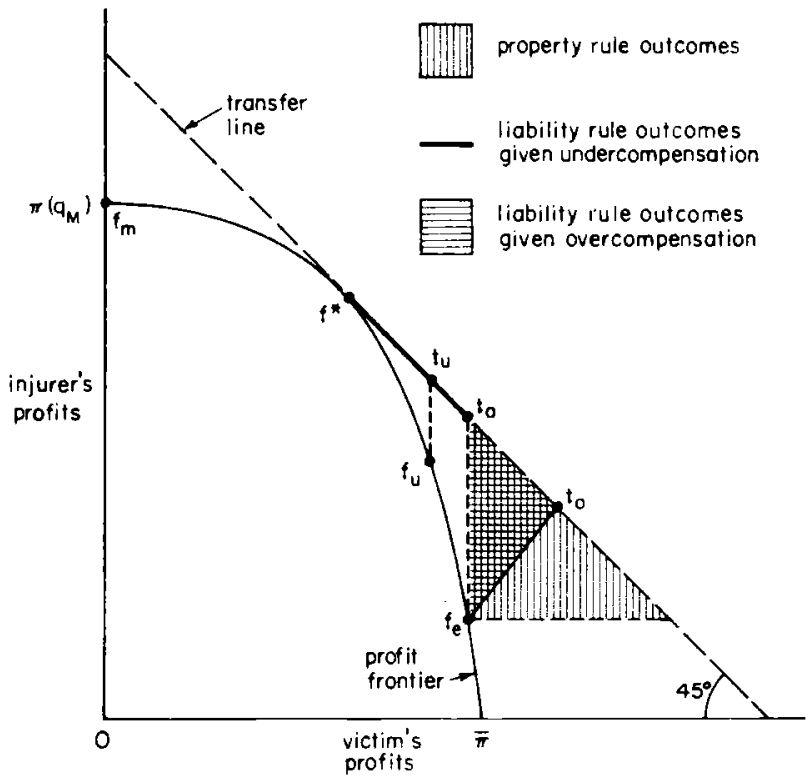


$\delta(q)=$ total damages to the victim,

$\bar{\pi}=$ fixed profits of the victim (before damages), ${ }^{7}$

$q^{*}=$ output at which joint prof its are maximized (the "efficient" output).

Given any output $q$, the injurer's profits are $\pi(q)$ and the victim's profits are $\bar{\pi}-\delta(q)$. It will be useful to derive the profits of the injurer as a function of those of the victim, assuming that only the output of the injurer can be varied and that the parties remain at this output. This relationship will be called the profit frontier. ${ }^{8}$ As one would expect, the injurer's profits are a decreasing function of the victim's profits. It will be assumed further that this function is strictly concave. A sufficient condition for this is that the victim's marginal damages are constant or increasing, which is a common assumption in externality analysis.

An example of this externality problem is illustrated in Figure 1 in terms of the parties' marginal schedules. The corresponding profit frontier is shown in Figure 2.9 There is a one-to-one relationship between points on the profit frontier and outputs of the injurer.

If the collective authority could use lump-sum transfers, it would, ideally, have the injurer produce at $q^{*}$ and then redistribute income to the extent desired. In terms of Figure 2, the set of attainable outcomes would be represented by a downward sloping $45^{\circ}$ line tangent to the profit frontier at the point on the frontier, $f^{*}$, corresponding to $q^{*}$. This will be called the transfer line. The point on this line which maximizes social welfare, given the collective authority's distributional preferences, is the first-best solution.

\section{PROPERTY RULES}

Property rules give each party the right to block any movement away from the entitlement point without that party's consent. By definition, if

7. It is assumed that $\bar{\pi}$ is sufficiently large so that the victim will remain in business regardless of the injurer's output (over the relevant range). If there were zero-profit opportunities elsewhere, this would be equivalent to assuming that $\bar{\pi} \geqslant \delta\left(q_{M}\right)$.

8. Let $x$ be some level of the victim's profits, so $x=\bar{\pi}-d(q)$. Solving for $q$ gives $q=d(\bar{\pi}-x)$, where $d$ is the inverse of $\delta$. Substituting this into $\pi(q)$ gives the desired relationship,

$$
\tilde{n}(x)=\pi(d(\bar{\pi}-x))
$$

It is easy to show (using the inverse function rule) that

$$
\tilde{\pi}^{\prime}=-\pi^{\prime} / d^{\prime}<0, \quad 0 \leqslant q<q_{M},
$$

and that

$$
\operatorname{sign}\left[\tilde{\pi}^{\prime \prime}\right]=\operatorname{sign}\left[\pi^{\prime \prime}-\pi^{\prime} d^{\prime \prime}\right] .
$$

9. In Figure 2 it is assumed for convenience that $\bar{\pi}=\delta\left(q_{M}\right)$, so that the victim's profits are zero when the injurer's profits are $\pi\left(q_{M}\right)$. 
the entitlement point does not correspond to the efficient outcome, there are potential gains from trade. But given strategic behavior, there is no guarantee that the parties will be able to agree on how to split the gains. Since each party has the right to remain at the entitlement point, any deviation from it that does occur must be a Pareto superior change. Thus, the set of potential outcomes under a property rule is defined by the entitlement point and consists of all feasible Pareto superior changes from that point. In general, there are a wide range of possible outcomes, depending on how close the parties bargain toward the efficient outcome and how they split the gains from trade.

The potential outcomes under a property rule are easily illustrated in terms of the externality problem and profit frontier represented by Figures 1 and 2. Suppose the entitlement point is at $q_{E}$ in Figure 1. There are potential gains from trade between $q_{E}$ and $q^{*}$ since it pays the injurer to "buy off" the victim to permit increases in the injurer's output. Given strategic behavior, the parties could end up anywhere in this range and could split the resulting gains in any way. The point on the profit frontier corresponding to $q_{E}$ is $f_{e}$ in Figure 2. The vertically hatched area represents all the potential outcomes under the property rule, given entitlement point $q_{E}$. If the parties were to bargain cooperatively, they would end up at $q^{*}$ in Figure 1. This would correspond to some point on the transfer line in the region which is Pareto superior to $f_{e}$ in Figure 2. The exact point would depend on how the gains from trade were split.

The previous discussion applies to every possible entitlement point. With one exception, the outcome under a property rule is indeterminate and, because of strategic behavior, not on the transfer line. The exception is when the entitlement point coincides with the efficient outcome. There are no potential gains from trade, so the parties remain there.

\section{LIABILITY RULES}

Liability rules give each party the right to compensation from the other party for the damages suffered as a result of the other party's deviation from the entitlement point. The amount of compensation is determined by the collective authority. Since what is taken from one party is given to the other, there are gains from trade if the entitlement point does not coincide with the efficient outcome. For reasons to be seen, certain restrictions on the schedule of liability are required to guarantee that the parties will exploit all of the gains from trade.

The potential outcomes under a liability rule are best illustrated in terms of the externality problem and profit frontier represented by Figures 1 and 2. Consider again the entitlement point $q_{E}$ in Figure 1 . Suppose the injurer's marginal liability beyond $q_{E}$ equals the victim's actual marginal damages, $\delta^{\prime}$. The injurer would then choose to produce at the efficient outcome, $q^{*}$, and the victim would be fully compensated 
for damages between $q_{E}$ and $q *$. Thus, the victim's profits would be the same as those at $q_{E}$ and the injurer's profits would be greater than those at $q_{E}$ by the gains from trade. Since the injurer produces at $q^{*}$, the outcome is somewhere on the transfer line in Figure 2. And since the victim's profits are the same as those at $q_{E}$, the outcome is that point on the transfer line directly above $f_{e}$ in Figures 2. This is point $t_{a}$ (" $a$ " for compensation equal to actual damages).

Suppose, alternatively, that marginal liability beyond $q_{E}$ is less than actual marginal damages. An example of such a liability schedule is labeled $\ell_{2}^{\prime}$ in Figure 1 (" $u$ " for undercompensation). Again, the injurer would choose to produce at $q^{*}$. But now the victim would be less than fully compensated for damages between $q_{E}$ and $q^{*}$, and the injurer's profits would be that much larger. Since the injurer produces at $q^{*}$, the outcome is still on the transfer line in Figure 2. And since the victim's profits are lower, it must be northwest of point $t_{a}$. This outcome is represented by point $t_{u}$, which, for reasons to be explained, must be between $t_{a}$ and $f^{*}$.

It is easy to see that an even lower liability schedule than $\ell_{u}^{\prime}$ in Figure 1 would lead to an outcome further up the transfer line than $t_{\mathrm{u}}$ in Figure 2. In the "limit," marginal liability could be zero until just before $q^{*}$ (but would then have to rise steeply to $\delta^{\prime}\left(q^{*}\right)$ at $\left.q^{*}\right) .{ }^{10}$ Thus, the best off the injurer could be made and the worst off the victim could be made corresponds to their profits at $q *$ In terms of the transfer line, this, of course, corresponds to point $f^{*}$ in Figure 2. By the appropriate choice of a marginal liability schedule which undercompensates the victim, any point on the transfer line between $t_{a}$ and $f^{*}$ - the darkened portion - could be achieved.

Finally, suppose that marginal liability beyond $q_{E}$ is greater than actual marginal damages, but less than the injurer's marginal profits. 11 An example of such a liability schedule is labeled $\ell_{0}^{\prime}$ in Figure 1 (" $o$ " for overcompensation). Although it might appear that the injurer would again be induced to produce at $q^{*}$, this is not so. Because the victim is overcompensated, the victim gains by increases in the injurer's output. By threats to not increase his output, the injurer can attempt to extort some or all of these benefits, $\ell_{0}^{\prime}-\delta^{\prime}$, from the victim. Of course, if the threat is carried out, the injurer loses too. But this is the essence of an extortion situation and, given strategic behavior, there is no guarantee that the injurer will end up producing at the efficient outcome, $q^{*}$. In general, the parties could end up at any output between the entitlement point, $q_{E}$, and $q^{*}$.

10. It is assumed that marginal liability cannot be negative. This assumption is motivated by institutional considerations. A victim suing an injurer for damages may lose, but his losing never results in his paying the injurer something (putting aside the issue of reimbursing the injurer for the cost of defending himself).

11. If marginal liability were to exceed $\pi^{\prime}$, the analysis would be essentially equivalent to the "limiting" case in which marginal liability equals $\pi$ '. This case is discussed below. 
When marginal liability exceeds actual marginal damages, the potential outcomes under the liability rule are a subset of the potential outcomes under the property rule with the same entitlement point. In terms of the entitlement point $q_{E}$ and the liability schedule $\ell_{o}^{\prime}$ in Figure 1 , it is the subset represented by the horizontally hatched area in Figure 2 . The reasons for this are as follows. Suppose, in terms of Figure 1, the injurer successfully extorts all of the victim's gains, $\ell_{o}^{\prime}-\delta^{\prime}$, no matter what output the parties end up at. The victim is still fully compensated for his damages beyond $q_{E}$ (since he would never be willing to pay more than $\ell_{0}^{\prime}-\delta^{\prime}$ ), so his profits are the same as those at $q_{E}$. The injurer's profits increase as a function of $q$ by the gains from trade. It is easy to see that, in terms of Figure 2, this corresponds to the line $f_{e} t_{a}$, the vertical boundary of the set of property rule outcomes.

Suppose, instead, that when the victim is overcompensated the injurer fails to extort any of the victim's gains. In these circumstances, both parties' profits increase monotonically as $q$ goes from $q_{E}$ to $q^{*}$, starting from their profits at $q_{E}$. These potential outcomes are represented in Figure 2 by the positively sloped segnent $f_{e} t_{o} .12$ This segment terminates at the transfer line since the parties cannot do better than when the injurer produces at $q^{*}$. Finally, if the injurer successfully extorts only a fraction of the victim's gains, the outcome will be represented by some interior point in the horizontally hatched area.

It is easy to see that an even higher liability schedule than $\ell_{0}^{\prime}$ in Figure 1 would expand the set of potential outcomes under the liability rule relative to that represented by the horizontally hatched area in Figure 2. In the "limit," marginal liability could be equal everywhere to the injurer's marginal profits. In this case, all of the gains from trade would be subject to extortion and the set of potential outcomes under the liability rule would be the same as that under the corresponding property rule.

The previous discussion applies to every entitlement point between zero and the efficient outcome, $q^{*}$. This implies that there is never an advantage to using inframarginal liability less than actual marginal damages in order to redistribute income from the victim to the injurer. Every outcome achievable in this way can be duplicated by liability everywhere equal to actual damages and the choice of a different entitlement point. Consider, for example, the liability schedule $\ell_{u}^{\prime}$ in Figure 1, which led to point $t_{u}$ in Figure 2. From the earlier discussion in this section, it is clear that the choice of the entitlement point corresponding to point $f_{u}$ on the profit frontier would, with liability equal to actual damages, also lead to point $t_{u}$. The same observation is true for any other point on the darkened portion of the transfer line.

The discussion in this section applies as well to entitlement points

12. The curvature of this segment is indeterminate without further assumptions. 
between the efficient outcome, $q^{*}$, and the injurer's profit-maximizing output, $q_{M}$. The only modification is that the role of the injurer and victim are reversed. In effect, the victim can choose the injurer's output but must compensate the injurer for his "damages" - foregone profits relative to the entitlement point. This is sometimes called a "reverse" liability rule. For analogous reasons, there is no advantage to paying the injurer less than his actual foregone profits; and there are extortion opportunities if the injurer is paid more than his actual losses.

\section{THE CHOICE}

The choice between property rules and liability rules depends on the technology of the externality, the distributional preferences of the collective authority, and the bargaining behavior of the parties. The relevance of these factors will be discussed in terms of Figure 3 (which shows the prof it frontier for a different externality problem than the one illustrated in Figure 1).

Given the technology of the externality, there are certain outcomes achievable by liability rules which are on the transfer line, and which are therefore Pareto superior to certain property rule outcomes. By setting laibility (normal or "reverse") everywhere equal to actual damages and varying the entitlement point from zero to the injurer's profit-maximizing output, $q_{M}$, any point on the darkened portion of the transfer line can be achieved. As Figure 3 makes clear, these liability rule outcomes dominate any outcome achievable by a property rule with entitlements corresponding to points on the profit frontier between $\underline{f}$ and $\bar{f}$. Figure 3 also shows that the segment of the transfer line along which liability rules are preferable to property rules is determined solely by the technology of the externality. In general, this segment can range from an arbitrarily small portion of the transfer line (in the "neighborhood" of $f^{*}$ ) to an arbitrarily large portion of the line.

The remaining outcomes which are not dominated by any liability rule are defined by the sets of potential property rule outcomes when the entitlement points are at the two extremes - zero output and the injurer's profit-maximizing output, $q_{M}$. In terms of Figure 3 , these entitlement points correspond to points $f_{z}$ and $f_{m}$ on the profit frontier, and the potential outcomes are indicated by the vertically hatched areas. For each point in these two regions, there does not exist a liability rule outcome on the transfer line which is Pareto superior to that point.

If the distributional preferences of the collective authority are such that the first-best solution lies on the portion of the transfer line achievable by a liability rule, then, of course, this liability rule would be preferable to any property rule. However, there is no reason to believe that this would occur in general since the authority's distributional preferences and the technology of the externality are unrelated. 
FIGURE 3

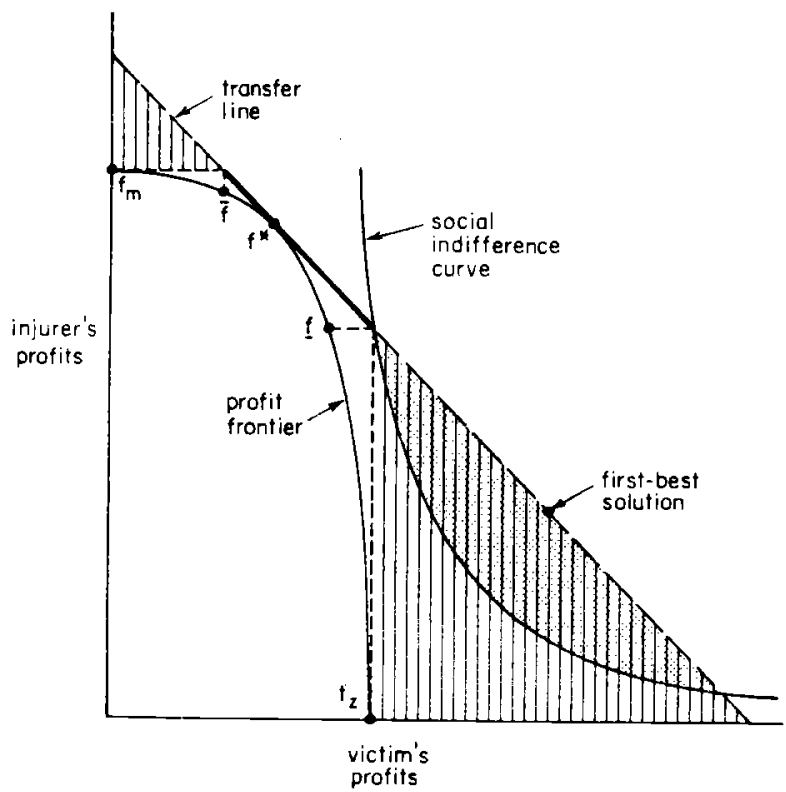

If the first-best solution does not lie on this part of the transfer line, then the choice between property rules and liability rules depends on the parties' bargaining behavior - how strategically they behave and how they split the gains from trade. This is illustrated in Figure 3 for the case in which the first-best solution is on the lower part of the transfer line. It is assumed that the collective authority's distributional preferences can be represented by (strictly convex) social indifference curves. ${ }^{13}$ The curve which goes through the "best" liability rule outcome on the transfer line is shown. (This outcome is achieved when the entitlement point corresponds to $f_{z}$ - zero output - and liability equals actual damages.) Every outcome in the shaded area is therefore socially preferable to this liability rule outcome. For every entitlement point corresponding to the points on the profit frontier between $f_{z}$ and $\underline{f}$, a property rule could lead to an outcome in this preferred area. Whether in fact the property rule outcome would be more desirable depends on the extent to which the parties bargain towards the "efficient" outcome, $q$ ", and how they split the gains from trade. As Figure 3 shows, however, if the parties do not split the gains too asymmetrically, there may be a wide range of property rule outcomes which are socially preferable to the best liability rule out-

13. Since the axes measure profits, not utility, the curvature of the social indifference curves has meaning. 
come on the transfer line even though the parties fail to bargain very close to $q^{*}$ under the property rule.

There is one final consideration in the choice between property rules and liability rules when the first-best solution is not attainable. Even though a property rule outcome may be preferable to the best liability rule outcome with liability equal to actual damages, it is necessary to consider whether a liability rule outcome with liability greater than actual damages might be even better. It was shown in section III that one effect of the latter type of liability rule is to limit the set of potential outcomes relative to the corresponding property rule (see Figure 2). In general, this effect is not necessarily desirable - and may be detrimental - since some of the excluded outcomes are Pareto superior to some of the remaining outcomes. However, the parties might be more likely to agree on how to split the gains when there is less scope for bargaining. Another effect of a liability rule with liability greater than actual damages is to reverse, relative to a property rule, the roles of the parties in terms of who does the threatening. For example, when the entitlement point is between zero output and the efficient output, $q^{*}$, the victim does the threatening under a property rule, whereas the injurer does the threatening under a liability rule with overcompensation. This effect might point either way, depending on which party is more stubborn.

\section{CONCLUSIONS}

The conclusions of this paper may be summarized as follows:

(1) The first-best solution - social welfare maximum - is achievable only in a (possibly very) restricted set of circumstances determined by the technology of the externality and the distributional preferences of the collective authority.

(2) When the first-best solution is feasible, only a liability rule can achieve it.

(a) Liability must be less than or equal to actual damages to avoid strategic behavior.

(b) Liability less than actual damages is never advantageous because the same outcome can be reached with liability equal to actual damages starting from a different entitlement point.

(3) When the first-best solution is not attainable, there is not a general case for liability rules or property rules.

(a) A property rule may be preferred to any liability rule with liability equal to actual damages if the parties do not bargain too strategically and if they do not split the gains from trade too asymmetrically.

(b) A liability rule with liability greater than actual damages may be preferred to a property rule because it restricts the scope for bargaining and reverses the roles of the parties with respect to threats. 
It is important to emphasize, finally, that the discussion here has been in a bargaining setting which is presumably most favorable to choosing liability rules. In practice, the collective authority - such as a court usually has imperfect information about the technology of the externality. This tends to further weaken the case for liability rules. ${ }^{14}$

\section{APPENDIX: MANY VICTIMS}

In externality situations involving a large number of individuals, it is often not practical to have the group represented by a single party. A simple variation of the previous discussion can be. used to analyze the choice between property rules and liability rules in this context. Only the case of one injurer and many victims will be considered since the other cases are easily developed from this one. It is assumed, for simplicity, that social welfare is a function of the injurer's profits and the victims' aggregate profits.

The outcomes under property rules now correspond to the profit frontier because, with many victims, no bargaining will take place. If, in terms of Figure 1, the entitlement point is between zero output and the efficient output, $q^{*}$, then bargaining will not occur because each victim has the power to block the injurer's increase in output and will attempt to be the "hold out." If the entitlement point is between $q$ " and the injurer's profit-maximizing output, $q_{M}$, then bargaining will not take place because each victim will attempt to take a "free ride" on the other victims" efforts to reduce the injurer's output.

The outcomes under liability rules are also affected by the presence of many victims. Suppose first that liability is equal to actual damages. (For the same reason as in section III, there is no advantage to having liability less than actual damages.) If the entitlement point is less than $q^{*}$, then each victim will have an incentive to obtain only his own damages. The holdout problem is avoided. However, if the entitlement point exceeds $q^{*}$, then each victim will attempt to take a free ride on the other victims' payments to reduce the injurer's output. As a result, no bargaining will take place.

Now suppose that liability exceeds actual damages for each victim. If the entitlement point is less than $q^{*}$, the injurer would not have an

14. For a detailed comparison of property rules and liability rules (and Pigovian taxes) when the government has imperfect information, see Polinsky (1979). Although that paper also briefly considered property and liability rules when the government has perfect information, it did so under a different set of assumptions than the ones used here and came to very different conclusions. Specifically, it was assumed that entitlements are exogenous (for example, determined by considerations of justice), rather than policy instruments to be chosen. Accordingly, the distributional goals of the government were assumed to take the special form of guaranteeing each party the profits it would have at the entitlement point. It was also taken for granted that liability was set everywhere equal to actual damages. Given these assumptions, the paper concluded that liability rules always do at least as well as property rules when the government has perfect information. 


\section{FIGURE 4}

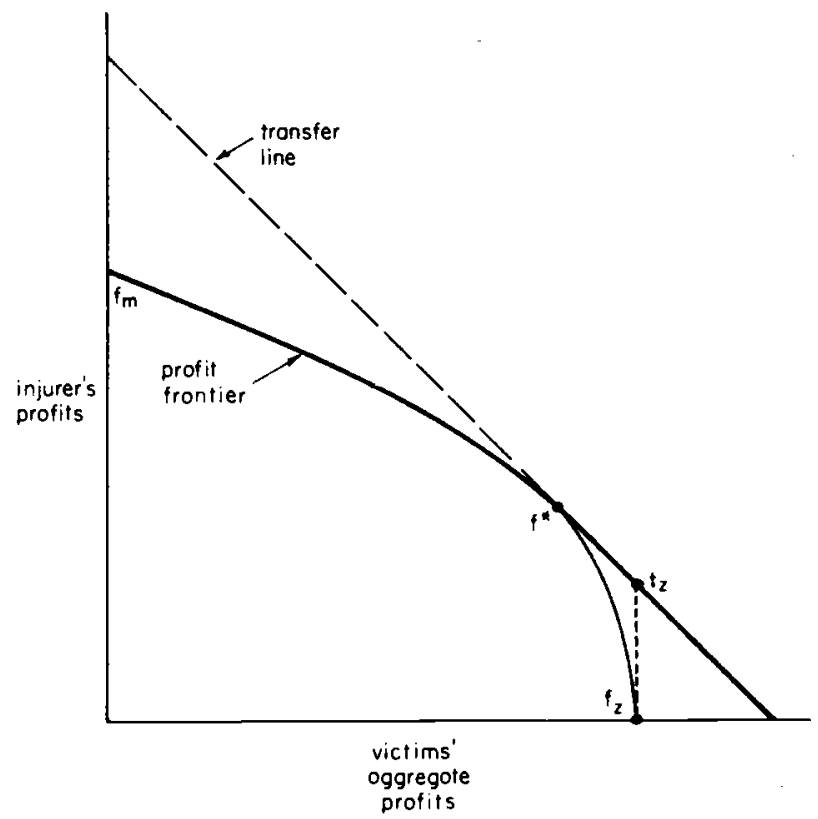

incentive to extort the victims for the following reasons. If, to avoid the threat of not increasing his output from being carried out, the injurer were to require that the victims as a class pay a certain amount of their aggregate gains, then each victim would attempt to take a free ride on the others' payments. The injurer, knowing that he would not obtain anything in this way, would therefore presumably produce at $q$ " and "allow" the victims to keep their gains. Alternatively, the injurer might require that each victim pay a specified portion of his gain in order for the threat not to be carried out. In this case, a version of the holdout problem would apply. Each victim would have an incentive to be the last one to pay, believing that the injurer would not forego all of his potential gains in order to get a fraction of that particular victim's relatively small gains. Again, knowing this, the injurer would presumably produce a $q^{*}$ and permit the victims to obtain their gains. Thus, when the entitlement point is less than $q^{*}$, it is possible to set liability greater than actual damages and still reach $q^{*}$. If the entitlement point is greater than $q^{*}$, however, the free rider problem applies and no bargaining will take place.

The combined set of (non-dominated) attainable outcomes is represented by the darkened line in Figure 4. Points on the profit frontier between $f_{m}$ and $f^{*}$ are achievable either by a property rule or a liability rule. Points on the transfer line between $f^{*}$ and $t_{x}$ are attainable by liability rules with liability equal to actual damages. And points on the 
transfer line below $t_{z}$ are achievable by liability rules with liability greater than actual damages.

Thus, when there is one injurer and many victims, liability rules do at least as well as property rules. However, the first-best solution is achievable by a liability rule only if it is on the segment of the transfer line below $f^{*}$ in Figure 4 . The size of this segment is determined by the technology of the externality and may be arbitrarily small.

\section{REFERENCES}

Calabresi, Guido, and A. Douglas Melamed, "Property Rules, Liability Rules, and Inalienability: One View of the Cathedral," Harvard Law Review, 85, No. 6 (April 1972), pp. 1089-1128.

Comment, "Internalizing Externalities: Nuisance Law and Economic Efficiency," New York University Law Review, 53, No. 1 (April 1978), pp. 219-240.

Elickson, Robert C., "Alternatives to Zoning: Covenants, Nuisance Rules, and Fines as Land Use Controls, University of Chicago Law Review, 40. No. 4 (Summer 1973), pp. 681-781.

Frech III, H.E., "The Extended Coase Theorem and Long Run Equilibrium: The Nonequivalence of Liability Rules and Property Rights." Economic Inquiry, 17, No. 2 (April 1979), pp. 254-268.

Organisation for Economic Co-operation and Development, Economics of Transfrontier Pollution (Paris: O.E.C.D., 1976).

Polinsky, A. Mitchell, "Controlling Externalities and Protecting Entitlements: Property Right, Liability Rule, and Tax-Subsidy Approaches," Journal of Legal Studies, 8, No. 1 (January 1979), pp. $1-48$.

Rabin, Edward, “Nuisance Law: Rethinking Fundamental Assumptions," Virginia Law Review, 63, No. 8 (December 1977), pp. 1299-1348. 